\title{
El derecho a la verdad en el genocidio de la Unión Patriótica
}

The right to the truth in the genocide of the Patriotic Union

Autor: Adriana Marcela Guerrero Martínez

DOl: https://doi.org/10.19053/16923936.v19.n38.2021.13691

Para citar este artículo:

Guerrero Martínez, A. M. (2021). El derecho a la verdad en el genocidio de la Unión Patriótica. Derecho y Realidad, 19 (38), 35-55. 


\title{
EL DERECHO A LA VERDAD EN EL GENOCIDIO DE LA UNIÓN PATRIÓTICA
}

\author{
The right to the truth in the genocide of the Patriotic Union
}

\section{Adriana Marcela Guerrero Martínez}

Maestría en Derechos Humanos

Universidad Pedagógica y Tecnológica de Colombia -UPTC-

amgm180@hotmail.com

Recepción: Diciembre 2 de 2020

Aceptación: Enero 20 de 2021

\section{RESUMEN}

Con el presente artículo se busca entender, explicar y abordar el concepto del genocidio como tipo penal internacionalmente repudiado y los antecedentes de la conceptualización del tipo, pues no es menos cierto que el concepto de genocidio se acuña jurídicamente hasta la segunda mitad del siglo pasado, como producto de las grandes guerras y las micro guerras que vivieron algunos Estados europeos con posterioridad a la Segunda Guerra Mundial. De esta manera, entender el concepto permitirá sentar las bases suficientes para abordar su aplicación en un estadio más específico como el del Estado colombiano.

Abordado el concepto general se analizará la aplicación normativa de que el Estado colombiano le dio al tipo del genocidio, ante la novísima adición del tipo por razones políticas, lo cual cambia la acepción original, dado que se entiende dentro de un contexto

inusual, atípico y extraño para la comunidad internacional y permite la investigación profunda del componente (de toda justicia transicional) de verdad dentro del reconocimiento de justicia, puesto que este es vital para dotar de reparación y garantizar la justicia, ya no solo a las víctimas, sino que también a toda la sociedad colombiana e internacional como elemento de integridad ente el aparato jurisdiccional, las víctimas, el gobierno nacional y la sociedad; y, por tal motivo, forjando un amplio grado de seguridad judicial general dentro del Estado colombiano.

\section{PALABRAS CLAVES}

Genocidio; Unión Patriótica; Derechos Humanos; Derecho a la verdad; justicia y reparación; víctimas.

* Artículo de reflexión 


\section{ABSTRACT}

This article seeks to understand, explain and address the concept of genocide as an internationally repudiated criminal type, and the antecedents of the conceptualization of the type, since it is no less true that the concept of genocide was legally coined until the second half of the last century as a product of the great wars and micro wars that some European states lived after the Second World War. In this way, understanding the concept will allow the laying of sufficient bases to address its application in a more specific stage such as that of the Colombian State.

Once the general concept has been approached, the normative application that the Colombian State gave to the type of genocide will be analyzed, given the newest addition of the type for political reasons, which changes the original meaning, since it is understood within an unusual, atypical and strange context for the international community and allows in-depth investigation of the component (of all transitional justice) of truth within the recognition of justice, since this is vital to provide reparation and guarantee justice, not only to the victims, but also to the entire Colombian and international society as an element of integrity between the judicial apparatus, the victims, the national government and society, and for this reason forging a wide degree of general judicial security within the Colombian State.

\section{KEYWORDS}

Genocide; Patriotic Union; Human Rights; Right to truth; justice and reparation; victims.

\section{INTRODUCCIÓN}

La guerra en Colombia, como casi cualquier proceso bélico, puede llegar a ser cíclica. Cada nueva vuelta ha significado el recrudecimiento de las formas anteriores de violencia, en las que los grupos dejan de lado sus ideales para convertirse en una facción más dentro del conflicto armado.
En el contexto colombiano, según las investigaciones del informe del Grupo de Memoria Histórica (Centro de Memoria Histórica, 2013), esta cuestión se ha venido incrementando, masificando y consolidando desde mediados de la década de 1990.

En el marco de este conflicto los gobiernos han buscado múltiples herramientas de mitigación, desde la vía armada, hasta la configuración de mesas de concertación política como por ejemplo el del entonces presidente Belisario Betancourt, quien a finales de los años 80 se sentó a dialogar con la Coordinadora guerrillera Simón Bolívar, encabezada por las Fuerzas Armadas Revolucionarias de Colombia- Ejército del Pueblo (FARC-EP), el Ejército Popular de Liberación (EPL), el Movimiento 19 de abril (M-19), el Ejército de Liberación Nacional (ELN) y la Autodefensa Obrera (ADO).

De esta mesa se estableció la formulación de normas tendientes al restablecimiento y preservación de la paz, a través de la cual se buscaba el acercamiento a los grupos insurgentes, y el paso de la guerra de guerrillas a la confrontación política de posiciones (Congreso de Colombia, 1982).

Producto de las medidas adoptadas surgió la Unión Patriótica como un movimiento pluralista y alternativo a los partidos tradicionales, que para entonces habían perdido credibilidad. Esta nueva opción, diferente de lo que se esperaba, resultó siendo tan fuerte que logró desestabilizar políticamente el mandato de las élites tradicionales, las cuales habían perpetuado la violencia desde el período que se conoce con el nombre genérico de La Violencia, hasta la consolidación de una dictadura, que terminó siendo "solucionada" con el proceso de alternancia gubernamental conocido como Frente Nacional.

La Unión Patriótica fue el resultado de la lucha contra la desigualdad y la pobreza, cuyo raigambre tendría un papel fundamental en la historia violenta del país. Sin embargo, este proceso que significaba para algunos una iniciativa de construcción y consolidación democrática, fue asumido por 
sectores de las fuerzas armadas como una completa oposición, puesto que implicaba la desnaturalización de las fuerzas políticas tradicionales y la pérdida del poder de cierta clase social.

Ante la creación de este movimiento y partido político se recrudeció la violencia armada que se tradujo en una serie sistemática de asesinatos contra los militantes de la Unión Patriótica, quienes ya habían sido objeto de amenazas relacionadas con su vida e integridad. Fueron sometidos a torturas físicas y psicológicas que provocarían el debilitamiento y casi extinción inmediata del partido. Este es -justamenteuno de los argumentos fundamentales que esgrime el colectivo de abogados defensores de derechos humanos que ha llevado el caso de la Unión Patriótica ante la CIDH para afirmar que no se trata solo de un caso de persecución política y vulneración al derecho de satisfacción de la verdad, sino que además constituye un crimen de lesa humanidad: el genocidio.

Surgió en este escenario el concepto del "derecho a la verdad", concebido como una consecuencia jurídica necesaria para toda situación de postconflicto bélico de carácter no-internacional, pero teniendo en cuenta las violaciones cometidas en contra del DIH y del DIDH. Muchos fueron los casos de los militantes de la Unión Patriótica que quedaron sin esclarecer, pero los familiares de las víctimas tienen derecho a conocer lo sucedido, a que los hechos sean investigados, esclarecidos y que los responsables sean sancionados.

Lo anterior, tiene profundas consecuencias no solo para la lucha de las instituciones colectivas en contra de la impunidad del genocidio, sino también para las garantías de no repetición. Una de las características fundamentales que resulta más problemática a la hora de abordar el derecho a la verdad es que, además de tener un carácter individual, en la medida en que son castigados los responsables de los hechos que se consideren violatorios de los derechos humanos, también es un derecho colectivo, en la medida en que se compromete a toda la sociedad (González, 2008, p. 435), justamente allí es donde radica la posibilidad de no repetición.

Es en este aspecto el presente trabajo busca analizar la manera en que el Estado colombiano aplicó el derecho a la verdad como garantía para las víctimas y sus familiares en el caso de la Unión Patriótica, examinar la postura que tiene a través de la legislación nacional y jurisprudencia vigente acerca del genocidio y las medidas de protección que ha elaborado para evitarlo, reconocerlo y resarcirlo.

En primera medida se estudian los antecedentes del genocidio; su definición, su reconocimiento a nivel internacional, enfocado en el reconocimiento del genocidio con fines políticos, por parte de entidades internacionales, como la Organización de Naciones Unidas (ONU), la Corte Penal Internacional (CPI). También se realizará un estudio sobre qué países de Latinoamérica han reconocido este tipo de genocidio, que, a su vez, permite identificar los mecanismos legales, tendientes a prevenir y sancionar el delito.

En el segundo capítulo se analiza el genocidio en Colombia. Se indaga el concepto de genocidio y genocidio político en Colombia, esto partiendo de considerar la existencia de un reconocimiento que amplía las garantías en esta materia por parte del Estado, ya que Colombia suscribió este tratado por medio de la Ley 28 de 1959 (Congreso de Colombia, 1959) y protegió este delito por el artículo 569 de 2000 (Congreso de Colombia, 2000, 06 julio) el cual, sufrió algunas modificaciones con ocasión del estudio de constitucionalidad que se efectuó en la sentencia $(C-177,2001)$ por ser violatorio de los derechos $5^{\circ}$, 11, 13, 28 y 107 de la Constitución Política (Ballén, 1991). A pesar de que no existe como antecedente de genocidio político propiamente dicho, se hará alusión al caso de los gaitanistas en Colombia.

En un tercer capítulo, se hace especial alusión al derecho a la verdad y se toma como referencia el análisis de las decisiones 
tomadas por la Corte Interamericana de los Derechos Humanos (CIDH) a razón del carácter vinculante que tienen sus sentencias para los Estados latinoamericanos que han admitido su competencia. Con ello, se podrá desentrañar la estructura que vincula los conceptos de verdad y de justicia, puesto que en caso de que se contemplaran las sanciones por responsabilidades individuales, resulta cardinal comprender que no existe justicia sin verdad, de la misma forma en que no existe verdad sin justicia.

Por último, se aborda teóricamente el caso de la Unión Patriótica haciendo algunas precisiones sobre el contexto histórico en el que se desencadenó este acto intencional atroz, que se perpetuó contra más de 650 líderes y simpatizantes de dicho partido (Mora, 2016) , puesto que su existencia suponía un riesgo para los intereses de unas clases sociales específicas. Así, se da cuenta de la forma sistemática en que la democracia colombiana se ha mantenido al margen de los atroces hechos que involucraron a personas de la oposición.

La finalidad de esta investigación es conocer si el gobierno colombiano otorgó medidas para mitigar estas situaciones, el trabajo que ha realizado de investigación, juzgamiento y sanción a las personas que fueron actores de la época de violencia en Colombia, si la totalidad de víctimas y sus familiares saben verdaderamente lo que ocurrió y si la situación se esclareció ante el país; o, si por el contrario, la democracia colombiana se ha mantenido al margen de atroces hechos que involucraron personas simpatizantes de la oposición.

\section{ANTECEDENTES DE GENOCIDIO}

\section{Referencia del genocidio en términos semánticos y gramaticales}

El concepto de genocidio se remonta a los juicios de la Segunda Guerra Mundial. Es allí donde el término fue utilizado por el doctor polaco Rafael Lemkin en su obra " $E l$ dominio del eje sobre la Europa ocupada". Este concepto se empleó para denominar la persecución y los delitos cometidos por el nacionalsocialismo alemán en contra de los judíos y gitanos. (Lemkin, 2008).

La concepción de genocidio, identificó la barbarie e inhumanidad en la que vivía la especie humana, la cual dista mucho de la racionalidad que le había caracterizado en el período de la Ilustración, o bajo la idea misma que promulgaba la "bondad natural del hombre" que no es otra cosa que el carácter consuetudinario, los hábitos racionales que se instituyen por medio de la sociedad (Rousseau, 2000). Se debe recordar que los actos allí cometidos lesionaron profundamente la dignidad humana, razón suficiente por la que estas operaciones fueran catalogadas como delito de lesa humanidad, es decir, el daño irreparable a una nación, a un grupo étnico, a un grupo religioso, a una raza o a un grupo político.

El término genocidio es una palabra grecolatina que surge de dos prefijos, uno de origen griego gen-genh que significa nacimiento (Pabón, 2002, p. 118), y del prefijo latino cidio, cidium, de la raíz de caedere, matar, acción de matar (Real Academia Española, 2014). Por lo que en su expresión literal genocidio traduce, según la Real Academia Española, como exterminio o eliminación sistemática de un grupo social por motivo de raza, de etnia, de religión, de política o nacionalidad (2014).

De acuerdo con el Equipo (Nizcor, 2007), el genocidio constituye una de las formas en las cuales se tipifica el crimen de lesa humanidad, definido desde el Estatuto de Roma (Organización de Naciones Unidad, 1998, p. 4), como un ataque con carácter sistemático contra la población civil perpetrado con conocimiento de causa.

La Corte reconoce delitos como el asesinato, el exterminio, la esclavitud, el encarcelamiento en casos en los cuales haya violación de las normas del derecho internacional, entre otras muchas formas en las cuales se incurre en una violación probada de los derechos humanos (Organización de Naciones Unidad, 1998); el hecho de que se reconozca el exterminio como crimen de lesa 
humanidad, remite la interpretación hacia el delito de genocidio, el cual, como se habría dicho en principio, tiene como característica fundamental la intencionalidad con la cual se perpetra.

\section{Reconocimiento del genocidio a nivel internacional}

En la Convención se reconocen al menos cuatro tipos de motivaciones por las cuales podría ser perpetrado el delito de genocidio: raza, etnia, religión y pertenencia a un grupo nacional. Estos fueron reconocidos en el ámbito internacional.

Cabe mencionar que en los dos años precedentes a la citada declaración de la ONU de 1948 se presentaron fuertes discusiones sobre si era posible que las razones políticas constituyeran un motivo legítimo para la tipificación del delito de genocidio. Tal discusión fue sorteada de manera que el genocidio político fuera excluido de las declaraciones de los estamentos y organizaciones internacionales, razón por la cual fue legitimado, en última instancia, el accionar genocida de los Estados (Feierstein, 2012; Huertas, 2006). Hoy en día a nivel internacional los grupos políticos no han podido acceder a ese manto especial de protección, argumentando, principalmente, la falta de delimitación específica de la población.

De igual forma, la Corte Penal Internacional no acepta la persecución de grupos políticos como genocidio en sus estatutos, pero lo inscribe en el Art 7 del Estatuto de Roma de la Corte Penal Internacional, se señala que la matanza generalizada o sistemática de miembros de un grupo político está en el marco de los crímenes de lesa humanidad, bajo la denominación de asesinato o de persecución (Huertas y Cáceres, 2015, p. 245).

A la negativa de incluir por parte de los Estados a estos grupos perseguidos, surge una solución salomónica de los tribunales internacionales y es la de incluirlo como un delito de lesa humanidad. Pero, no se puede decir con certeza que exista una verdadera garantía sobre este delito toda vez que este desconocimiento jurídico puede dar paso a la vulneración de la igualdad como derecho inalienable $y$, además, configurar una discriminación frente a los diversos grupos perseguidos.

En Latinoamérica Colombia, Panamá, Paraguay y Costa Rica se han sumado a la protección de los grupos políticos en la tipificación del genocidio; mientras que Perú y Bolivia fueron sociedades más garantistas, debido a que hicieron expresa la protección de los grupos sociales en general, lo cual conlleva a ampliar el marco de protección declarado por el Estatuto de Roma.

\section{El caso del genocidio armenio (1915-1917)}

A finales del siglo XIX se registraron las primeras evidencias de agresiones en contra del pueblo armenio (Ferraro, 2015) y se estableció que en abril de 1915 se dio inicio al exterminio, con el arresto de un grupo de intelectuales armenios por las autoridades turcas. Como en el caso alemán, el genocidio de los armenios tiene la particularidad de gobernanza ejercida por un partido único -nacionalsocialismo-, que les daba a los jóvenes turcos en el imperio Otomano la tranquilidad y la fortaleza de tener a su disposición el poder político, civil y militar; lo cual les daba supremacía sobre los civiles desarmados.

\section{La construcción de una identidad negativa}

En los límites del imperio vivían cristianos, griegos, musulmanes y armenios, quienes convivían con cierta autonomía en agrupaciones cuyas particularidades dieron a la luz del mundo un gran acervo cultural. Con la decadencia del imperio por el siglo XVII, el proceso expansivo se detuvo; especialmente cuando se evidenció la necesidad de cambios estructurales, que consistían en modificar el sistema militar con un método más riguroso, pero para esto se requirió inversión que fue suplida como préstamo por parte de Europa. 
Las luchas internas pugnaban por la igualdad, la instauración de derechos ciudadanos y por una reestructuración desde los mismos cimientos, que terminó con la implementación de una Constitución en 1876 que rigió dos años hasta que fue anulada por el sultán Abdul Hamid II (recordado como el Sultán Rojo o el "Gran asesino").

De 1885 en adelante, los procesos políticos de resistencia del pueblo armenio tendrían eco en el ámbito internacional, que hizo que la comunidad internacional interviniera en su defensa. Además, se conformaron partidos como la Federación Revolucionaria Armenia o el Partido Hunchakian (Granovsky, 2014, p. 24).

La legitimidad del Estado era cada vez más cuestionable, de manera que en abril de 1908 fue derrocado el sultanato (24 de abril de 1908), lo cual terminó en festejos por parte de otomanos y armenios por el cambio del régimen (Granovsky, 2014, p. 13).

El derrocamiento del sultanato significó para los armenios una agudización y sistematización de las prácticas genocidas, sustentadas en la interiorización de la justicia de las acciones del sultán en contra de las minorías étnicas, específicamente hacia los armenios, a quienes se les endilgó la decadencia y caída del Imperio Otomano.

Lo anterior llevó a que el gobierno turco respondiera de manera tal que surgió en 2015 el plan de exterminio, tal y como lo reseñara Granovsky (2014), quien habló de la existencia de un plan secreto en contra de los armenios, que sería puesto en práctica una vez hubiese ocasión.

\section{El exterminio del pueblo armenio}

En la Primera Guerra Mundial, el 24 de abril de 1915, en Estambul fueron detenidos al menos 600 intelectuales armenios, hombres entre los 14 y 45 años, a quienes se les enlistó en el ejército turco y se enviaron a la guerra sin dotarles armas, siendo usados como mano de obra para la construcción de trincheras que se convertirían en sus tumbas (Morgenthau, 1975).
El ministro de defensa turco ordenó que fueran asesinados de formas tan crueles que entre el propio ejército turco hubo renuencia con las órdenes de tortura (Granovsky, 2014 , p. 14), por lo que fueron sometidos a terribles suplicios, como asesinatos con armas blancas y ahogamientos.

En 1923, mediante un proceso electoral, llegó a la magistratura turca Mustafá Kemal, bajo la consigna de "Turquía para los turcos", situación que no cambió sustancialmente para los pueblos minoritarios. Entre sus propósitos gubernamentales declaraba el respeto por los derechos humanos sin distingo de raza, sexo o religión, pero la realidad fue distinta para quienes constituían la minoría excluida.

\section{Tratamiento de la comunidad internacional}

Aun cuando alrededor del mundo la discusión sobre la existencia de genocidio en contra del pueblo armenio no necesita de pruebas adicionales, oficialmente solo una pequeña parte de la comisión compuesta por veintisiete países lo habrían reconocido hasta 2016, año en el cual se conmemorarían los 101 años de los atroces acontecimientos (Cabrera, 2019).

El Papa Francisco I -jerarca de la Iglesia Católica- señaló en un discurso del 24 de junio de ese año, que aquel genocidio inauguró la lista de terribles catástrofes del siglo pasado, causadas por motivos raciales, ideológicos o religiosos, que cegaron la mente de los verdugos hasta el punto de proponerse como objetivo el aniquilamiento de poblaciones enteras (2016).

La comunidad internacional se pronunció ante las violaciones perpetradas contra los jóvenes turcos en su proyecto "pan-turco", como fuera calificado el empeño de los turcos por instituir una patria para ellos y los suyos, exterminando a los demás, según lo expresó el entonces emisario de Washington (Morgenthau, 1975). De hecho, gracias a la actividad de denuncia por parte de los cristianos protestantes que intentaban ganar adeptos en el medio oriente, la situación 
del pueblo armenio fue conocida por la comunidad internacional (Granovsky, 2014).

En 2014, el primer ministro del interior turco, declaró que el Estado, enviaba un sentido pésame a las víctimas de las matanzas cometidas en el marco de la Primera Guerra Mundial, señalando enfáticamente, que no fue un genocidio, negando los hechos e incluso en su justificación, manteniendo la versión según la cual para el Estado turco no se trató de un genocidio sino de una consecuencia del tiempo conflictivo de la época (Ruiz, 2014).

El 15 de abril de 2015 en un artículo se sostiene que ante la solicitud al Estado turco por parte de la cámara de la Unión Europea (UE), para el reconocimiento del genocidio en contra del pueblo armenio, sus representantes no solo se negaron ante la petición elevada, sino que argumentaron que tal petición habría sido alentada por motivos de intolerancia religiosa (El Mundo, 2015).

\section{EL GENOCIDIO EN COLOMBIA}

\section{Reconocimiento del genocidio y genocidio político en Colombia}

Para hablar de genocidio en Colombia se debe hacer alusión a la Ley 28 de 1959, por medio de la cual se aprobó la Convención de las Naciones Unidas para la Prevención y Sanción del Delito de Genocidio, a través de la cual el Estado se comprometió a tipificar como delito y sancionar severamente las conductas consideradas como crímenes de lesa humanidad.

En Colombia se dicta la Ley 589 de 6 de julio del 2000, en su artículo 322A, donde se tipifica el genocidio como un delito y se indica la pena entre 45 a 60 años y multa de 500 a 2000 salarios mínimos legales mensuales vigentes. (Ley 589, 2000. Art 322) Con ella, el Estado busca la defensa de los derechos fundamentales de los ciudadanos y el Art 322 presenta la tipificación del delito de genocidio, que dan cuenta del carácter de protección a los derechos a la vida y a la integridad en condiciones de igualdad.
La Corte mediante jurisprudencia deja claro que lo que se busca es la ampliación de la protección del genocidio, que surge de vincular a los grupos políticos como posibles víctimas de este delito, pues es sabido que la regulación contenida en los tratados y pactos internacionales consagra un parámetro mínimo de protección, de modo que nada se opone a que los Estados, en sus legislaciones internas, consagren un mayor ámbito de protección. Y no se puede ignorar que en Colombia muchos de los exterminios que podrían ser caracterizados como genocidio son de naturaleza política.

El hecho de que Colombia haya reconocido el delito de genocidio político, no es otra cosa que la ampliación de garantías para la preservación de derechos y el adecuado proceder respecto a ese delito, lo cual acrecienta la misión del Estado para a garantizar la defensa de los derechos, de modo que este no contradice su legislación interna, pero sí otorga un mayor ámbito de protección. Incluso, Colombia hace suyas las recomendaciones de la CPI, en cuanto este organismo conmina a los Estados a adoptar medidas tendientes a someter estas acciones a la justicia, en la lucha contra la prevención de este delito, pero conservando la esencia de este crimen, que consiste en la destrucción sistemática y deliberada de un grupo humano que tenga una identidad definida. Y para Colombia es indudable que un grupo político la tiene.

\section{Antecedentes de genocidio a nivel interno}

El caso del genocidio al movimiento Gaitanista. Quizá una de las características más inquietantes del período conocido como La Violencia (1946-1958) es que aun cuando las dirigencias de los partidos tradicionales (Liberal y Conservador) estuvieran al frente de las banderas de la oposición, eran los afiliados a los partidos: el pueblo, quienes dirimían los conflictos por el poder en los territorios. Pero, según las estadísticas oficiales, zanjar esos conflictos significó que entre 1949 y 1957 se contaran al menos 16.219 personas muertas, otras tantas desplazadas de manera forzosa $y$ 
muchas más que vieron reducir a cenizas sus pertenencias (Centro de Memoria Histórica, 2013).

La cruda violencia se desató con fuerza hasta el asesinato del líder político del Partido Liberal: Jorge Eliécer Gaitán, el 9 de abril de 1948; evento que desencadenó uno de los periodos más atroces en la historia del país. Se conformaron, entonces, los grupos de autodefensa campesina y las guerrillas liberales, así como colectivos nombrados "chulavitas" o "pájaros" que actuaban bajo las órdenes del Partido Conservador.

\section{La identidad negativa}

La década de 1940 encontró al país en la consolidación de nuevas dinámicas de violencia que estallarían en el proceso conocido como Restauración Conservadora. Entre 1946 y 1953, el entonces presidente de Colombia y líder del Partido Liberal, Alfonso López Pumarejo (1934-1938\19421946) vio cuestionada la legitimidad del Estado por acusaciones de corrupción por conservadores liderados por Laureano Gómez y empresarios, el Partido Liberal empezó a dividirse.

Con el Golpe de Pasto, quedó demostrada la participación de las fuerzas militares en enfrentamientos de carácter político (Pérez, 2018), con participación militar en dichos asuntos a pesar de la prohibición constitucional. Según el Grupo de Memoria Histórica, esta situación constituyó una de las razones de agudización de la violencia: "A ello se sumó la intervención de la Iglesia Católica a favor del Partido Conservador, hecho que dio una justificación moral y religiosa al discurso antiliberal y anticomunista (Centro de Memoria Histórica, 2013).

La situación política iba cada vez tomando matices más crueles, la economía del país daba la idea de que el progreso era posible, ya que las organizaciones sindicales actuaban en favor de los intereses de la clase obrera (Centro de Memoria Histórica, 2013).

La división política se hizo cada vez más patente, especialmente para las elecciones del período 1946-1950, a las que se presentaron Jorge Eliécer Gaitán y Gabriel Turbay (El Tiempo, 1999). Luego de 16 años en poder del Partido Liberal, la división dio paso a la gobernanza del líder del partido Conservador, Mariano Ospina Pérez, quien era "el caballo de Troya de Laureano" (Molano, 2015). Por otra parte, Gómez instaba a la guerra civil; las centrales obreras llamarían a las protestas más grandes que hasta ese momento hubiera visto volcadas en las calles de las ciudades contra el vertiginoso aumento del costo de vida y buscando la dimisión del presidente electo (Torregrosa, 2009).

En 1947 Jorge Eliécer Gaitán asume la dirección del Partido Liberal, luego de que Gabriel Turbay huyera al exterior y el gobierno de Ospina Pérez buscaba la conversión al conservatismo de las fuerzas militares (Molano, s.f.; Torregrosa, 2009). Este movimiento fue decisivo, pues supuso la consolidación de un orden social afín con los intereses conservadores y eclesiales (Centro de Memoria Histórica, 2013); por ello, ante la propuesta del Partido Liberal acerca de formar a la Policía como una institución cuya jurisdicción correspondiera al congreso de mayoría liberal, pero la respuesta desde el Ministerio de Justicia fue que la defensa contra la propuesta liberal sería a "sangre y fuego" (Molano, s.f.).

La violencia política habría de arreciar en el campo como en la ciudad. Gloria Gaitán, hija del fallecido político, sostiene que dentro del archivo personal de su padre se encontraban numerosas pruebas sobre la responsabilidad del gobierno $y$, en especial del Partido Conservador, sobre los crecientes ataques contra los militantes del Partido Liberal cuyas denuncias eran allegadas al despacho de Jorge Eliécer Gaitán (Las 2Orillas, 2014).

De 1945 en adelante, los militantes del Partido Liberal, que ponían su confianza en Gaitán, conocidos posteriormente como gaitanistas, fueron sistemáticamente exterminados. En el cuarto punto de la misiva la señora Gaitán señalaba que existían pruebas que demostraban que por parte del 
coronel Virgilio Barco habían contratado personas para generar conflicto, insistía en que lo ocurrido fue una violencia oficial, desatada en forma premeditada, sistemática y generalizada por el Estado colombiano". (Vallejo, 2016).

El proceso genocida. No se encuentran muchos informes que señalen la existencia de un proceso genocida sobre los simpatizantes de Gaitán. Este período se ha enmarcado frecuentemente en la época conocida como La Violencia, ubicada entre mediados de la década de 1940 y de 1960 . Si se entiende como genocidio la acción de carácter intencional cuyo objetivo es exterminar a un grupo humano determinado (ONU, 2018b), en el caso gaitanista ha estado cubierto por el manto de la historia oficial.

Durante esa época miles de personas fueron asesinadas, despojadas, torturadas, exterminadas, en razón de sus convicciones políticas. Como se ha dicho, las ideas de Gaitán representaban una amenaza para las élites del país y cada vez más personas se sumaban a sus ideas, pues concebía que la política debía estar regida por los principios morales, de modo que fuera posible el progreso del país.

El diario El Espectador reseñó en ediciones de esa época, que el presidente Alberto Lleras Camargo del Partido Liberal, llamó a los dirigentes del conservadurismo y a los liberales simpatizantes de Turbay a impedir la llegada de Gaitán al poder; quien de acuerdo con el testigo "reforzó las garantías diciendo que, si tenía que echar una bomba de dinamita sobre Soatá para que dejaran votar a los conservadores, lo haría. Al fin pudieron votar y ganar, como era previsto" (Valencia, 2011, párr. 11).

Cuestiones como estos muestran el carácter intencional de exterminar a un grupo humano; en este caso los gaitanistas, cuya visión política resultaba cada vez más problemática para los intereses de las élites.

Así como se señala en las investigaciones del Centro de Memoria Histórica, la violencia fue en sus formas represivas contra de los militantes del movimiento gaitanista y se volvió más aguda tras la muerte del prócer liberal. Los eventos en los cuales ocurre su deceso pasarían a la historia como El Bogotazo (2013).

Es entonces clara la provocación contra el grupo político emergente. La acción última y quizá la más provocadora fue en efecto el asesinato del líder político de esta colectividad (Oquist, 1978; Pécaut, 2003). Tal y como ha venido insistiéndose, lo que vino después de estos hechos fue el levantamiento rebelde de porciones liberales de la población, que fue respondido de forma aún más violenta por parte de los gobernantes conservadores. El descuartizamiento y la tortura se convirtieron en mensaje y fueron el sello distintivo de esa violencia que no termina del todo (Uribe, 2004b).

\section{El encubrimiento}

El proceso de encubrimiento, tal y como se observó en el caso del pueblo armenio, tiene consecuencias duraderas, de forma tal que, en muchos de los casos, no se reconoce el genocidio. En Colombia ese proceso no ha sido diferente.

Esta época ha sido caracterizada como una contienda bipartidista, cuando lo que se ha mostrado es el carácter intencional de la violencia en contra de los simpatizantes del líder político Jorge Eliécer Gaitán, lo que marcó un terrible episodio de la historia que respondió al plan de las élites nacionales para mantener su posición en equilibrio. (Biblioteca Nacional de Colombia, 2020).

La persecución sistemática a las colectividades que se identifican en la diferencia, con proyectos políticos diferentes, que pudieran significar la pérdida del poder para las clases políticas nacionales, ha permitido una comprensión más profunda de los años que vinieron luego, en los cuales esta persecución, lejos de mermar, encontró su correlato en nuevas acciones en las cuales fueron exterminadas colectividades con sesgos políticos diversos. 
Así como este caso del gaitanismo, ha habido otros durante la historia colombiana que han sido similares pero que no se han aceptado como genocidio político, donde el gobierno se lava las manos reiterando que son situaciones que han pasado durante ese tiempo específico de la historia, casos como el de la violencia en Trujillo, que no se sabe si fue masacre, homicidio múltiple o genocidio. Allí en un grupo de personas fueron asesinadas, desaparecidas, secuestradas y torturadas, los instrumentos utilizados para esta barbarie fueron las sierras eléctricas y los responsables están en libertad. Solo hasta 1995 el presidente de ese entonces aceptó responsabilidad por parte del Estado colombiano por la violencia vivida en Trujillo, pero a pesar de aceptar la responsabilidad todo quedo en ese discurso, porque aún muchas personas siguen sin conocer la verdad sobre lo ocurrió con sus familiares.

Otro suceso fue el asesinato del senador Manuel Cepeda Vargas, hecho en el que se involucra a miembros del Ejército Nacional y a jefes paramilitares. Este caso está siendo revisado por la $\mathrm{CIDH}$, pero no ha sido aceptado por parte del Estado.

A los grupos políticos Alianza Unión Nacional de Oposición (UNO) y Frente Democrático, también les asesinaron a sus líderes.

Cuando Álvaro Uribe Vélez inició su campaña electoral manifestó que "no se puede combinar política con fusiles" (Uribe V., Álvaro. Manifiesto democrático. 100 puntos del programa de Gobierno. http://www.alvarouribevelez.com.co/) haciendo referencia a lo sucedido con la Unión Patriótica y aseguró que su gobierno respetaría a la oposición, situación que fue errónea, debido a que se presentaron nuevas modalidades como detenciones arbitrarias, procesos judiciales manipulados mediante testigos y así ha pasado durante los otros gobiernos de otros presidentes, quienes no han realizado las acciones pertinentes para evitar la persecución de líderes sociales y grupos políticos, al igual que no han garantizado el derecho a la verdad de las víctimas.

\section{EL DERECHO A LA VERDAD}

\section{Evolución y desarrollo jurisprudencial}

El derecho a la verdad, definido desde las instancias jurídicas internacionales, es entendido como el derecho que tiene toda víctima de conocer la verdad sobre los hechos ocurridos en el marco de situaciones en las que ha sido violado el Derecho Internacional Humanitario o el Derecho Internacional de los Derechos Humanos (González, 2008; Pérez, 2013 y Becerra y Pava, 2016).

El llamado derecho a la verdad no posee -desde el punto de vista de la opinio iurisun origen determinado y, sin embargo, suele ser considerado como un derecho situado en la base del DIH (Guzmán, 2012). El primer enunciado jurídico que le otorga fundamento es el Protocolo I a los Convenios de Ginebra de 1949, especialmente en el artículo 32, que se refiere a la sección de "fallecimiento" y de "desaparición" de personas en el marco de conflictos armados.

Se trata entonces del derecho que tienen las familias de conocer la suerte de sus miembros, cuestión que desplaza la titularidad y el beneficio del derecho más allá de las víctimas directas del conflicto hacia sus víctimas indirectas. Sin embargo, las organizaciones internacionales, por medio de tratados de derecho internacional público, fueron imponiendo a los Estados nacionales obligaciones especiales que les suponían la investigación, el esclarecimiento y sanción de violaciones al DIH en casos de desapariciones, ejecuciones extrajudiciales, desapariciones forzadas y tortura. Este es el punto en el que el derecho a la verdad adquiere nuevas dimensiones. (Salmón, 2004)

Pero fue solo hasta el Informe Anual presentado por la CIDH (1985-1986) donde se reconoció la existencia de un derecho a la verdad y lo definió como un derecho 
irrenunciable, para los familiares de las víctimas y para la sociedad civil, de conocer la verdad sobre los delitos cometidos en contra de la dignidad de los seres humanos en el marco de los conflictos armados.

En América Latina el derecho en cuestión, fue solo hasta 1969 que en la Convención Americana de Derechos Humanos los temas jurídicos inscritos en este régimen fueron objeto de un tratado con fuerza vinculante, a saber: el llamado "Pacto de Derechos Civiles y Políticos” (Dulitzky, 2007; Faúndez, 2007).

A partir de aquí se creó la Corte Interamericana de Derechos Humanos (CIDH) la cual, al ser dotada de ciertas facultades, hizo que se convirtiera en el órgano principal de la OEA. Teniendo en cuenta esto Becerra y Pava (2016) afirman que: la verdad ha tenido un desarrollo conceptual que pasa por diferentes perspectivas, para ligarse a los Derechos Humanos como una forma de garantizar el conocimiento de los hechos, preservar la memoria y prevenir la impunidad. (Becerra y Pava, 2016, p. 124).

En el 2000, el caso Bámaca Velázquez vs. Guatemala, la sentencia de la CIDH formuló expresamente el derecho a la verdad de manera que este sería concebido como un derecho subsumido en los derechos de las víctimas y familiares, quienes podrían exigir al Estado el esclarecimiento de los hechos violatorios y de las responsabilidades correspondientes. En efecto, inspirada en los artículos 8 y 25 de la Convención Americana de Derechos Humanos la CIDH. (Corte Internacional de Derechos Humanos, 2000, p. 82).

En la sentencia sobre el caso de la Masacre de Mapiripán vs. Colombia que fue emitida el 15 de septiembre de 2005, la Corte estableció el cumplimiento de un plazo razonable para el proceso de esclarecimiento penal, esto como un nuevo elemento, a propósito de la sanción a las ejecuciones extrajudiciales y de los criterios de estándares internacionales de verdad, justicia y reparación. Este desarrollo es lo que ha hecho que, pese a no estar expresamente formulado en la Convención
Americana de los Derechos Humanos, la CIDH se haya convertido en una institución protectora y garante del derecho a la verdad.

Durante el 2000, los casos Durán Ugarte vs. Perú y Bámaca Velásquez vs. Guatemala hicieron que la CIDH reconociera la necesidad de establecer las bases jurídicas con las que sería posible comprender a los familiares de las víctimas como sujetos del derecho a la verdad (González, 2008); (Guzmán, 2012); (Becerra y Pava, 2016). Sin embargo, la Corte fue dando importantes pasos en favor de su reconocimiento.

En los casos "Paniagua Morales y otros vs. Guatemala" y "Niños de la Calle y otros vs. Guatemala, se sentaron nuevos precedentes, especialmente la sentencia dictada a propósito de los "Niños de la Calle" (González, 2008), (Fajardo, 2012). Como se sabe, en esta última el pronunciamiento la Corte estableció como obligación del Estado la designación de centros educativos en memoria de las víctimas de la tortura y las ejecuciones extrajudiciales y, por la misma vía, se impuso la obligación de poner placas con los nombres de los niños identificados como víctimas de los hechos violatorios de los derechos fundamentales.

\section{Elementos estructurales}

En primer lugar, uno de los momentos fundamentales respecto de la satisfacción del derecho a la verdad, en lo que al proceso judicial se refiere, es la identificación de los responsables de las conductas y hechos violatorios del DIH y el DIDH, en lo tocante a la responsabilidad que le cabe a los Estados dentro del juzgamiento de las violaciones a los derechos humanos ocurridas bajo su potestad; se encuentra que el desarrollo jurisprudencial registrado en los Convenios de Ginebra de 1949 no contempla explícitamente, que en el ámbito restringido de los conflictos de carácter no internacional sea responsabilidad del Estado, llevar a término satisfactorio estos procesos.

En segundo lugar, el Protocolo II dentro su artículo 6.5, contempla la facultad del Estado Nación para el otorgamiento de amnistías. 
Esta prerrogativa no habría de cobijar, ni de actuar, bajo ninguna circunstancia en favor del encubrimiento de delitos que constituyan violaciones graves contra los derechos humanos (Salmón, 2004); (Núñez, 2011). La referencia a otorgar una "amnistía lo más amplia posible" no debe ser interpretada más que en el estricto sentido de la violación de normas penales dentro del derecho interno. Desde este punto de vista, la virtualidad del derecho a la verdad impone a los Estados la asunción plena de los compromisos jurídicos internacionales de tal manera que la legislación interna no puede ser, en ningún caso, una excusa para su desconocimiento (González, 2008) (Becerra y Pava, 2016).

En tercer lugar, en relación con las normas de indulto que se establezcan en favor de los responsables de graves violaciones al Derecho Internacional de los Derechos Humanos o el Derecho Internacional Humanitario, González (2008) sostiene que aún en cuanto la satisfacción del derecho a la verdad no resulte imperativa la expedición de una condena, a menos que así se establezca, el derecho internacional sí obliga a la consumación de dicha exigencia de manera tal que la CIDH ha declarado la prohibición de aplicar normas de indulto a este tipo de casos; ello en razón a que prevalece el derecho de las víctimas tanto directas como indirectas de crímenes de lesa humanidad.

En cuarto y último lugar, es necesario tener en cuenta que, a razón de las experiencias testimoniadas de víctimas, las violaciones sistemáticas a los derechos humanos y por lo tanto a la dignidad humana de las personas por parte del Estado y de organizaciones afines, surge la necesidad de superar este flagelo que se ha convertido en una prioridad de las sociedades contemporáneas Comisión Colombiana de Juristas, 2006); (Rincón, 2010).

Con el propósito de asegurar la protección de las víctimas, el derecho internacional de los derechos humanos ha plasmado toda una serie de normas y principios relativos al contenido y al alcance de los derechos a la verdad, la justicia y reparación. Es evidente que estas normas y principios funcionan como guía para la estructuración de los procesos particulares, pero también es evidente que son las víctimas quienes deben determinar cuáles serían los mecanismos más adecuados para restablecer sus derechos vulnerados.

\section{Colombia y el derecho a la verdad}

El derecho a la verdad no solo es reconocido internacionalmente, sino también a nivel nacional, es por ello que se plasmará como Colombia reconoce este derecho a los ciudadanos que han sido víctimas por hechos ocurridos en el país. Este derecho consiste en la obligación que tiene el Estado de investigar, juzgar y sancionar las violaciones a los derechos humanos que han sido perpetradas en la sociedad, cuando se refiere a violaciones de derechos humanos son acciones como: genocidio, tortura, desapariciones forzadas y apartheid, donde la verdad es el derecho que le asiste no solo a la víctima, sino a la sociedad.

El Estado mediante doctrina jurisprudencial ha aceptado la naturaleza del derecho a la verdad, donde la Corte Constitucional ha afirmado que las víctimas tienen derecho a saber la verdad porque de esa manera se estaría combatiendo la impunidad; por lo cual analiza dos vertientes, la primera es el derecho que le asiste a las víctimas y sus familiares y, la otra, es el derecho que tiene la sociedad de estar informada de los sucesos que conlleven la violación a los derechos humanos. (Corte Constitucional Colombiana, sentencias T-249 de 2003; C-228 de 2002, C-580 de 2002 y C-458 de 2006.)

De igual manera la Corte Constitucional mediante la sentencia C-454 de 2006, indica que el derecho a la verdad es:

El conjunto de principios para la protección y la promoción de los derechos humanos mediante la lucha contra la impunidad (principios 1 a 4), donde incorporan en este derecho las siguientes garantías: (i) el derecho inalienable a la verdad; (ii) el deber de 
recordar; (iii) el derecho de las víctimas a saber. (Corte Constitucional, 2006).

La Corte realizó esa clasificación con la justificación de que cada ciudadano tiene derecho a conocer la verdad de los sucesos o circunstancias que incentivaron la realización de los crímenes, al igual que el derecho a conocer de la historia, para que con ella se adopten medidas para evitar más hechos de esa índole y, por último, que las víctimas tienen el derecho imprescriptible de saber la verdad independientemente de los procesos que llegaren a iniciar, por ser un deber que tienen de saber lo que sucedió con sus familiares.

Con la Ley 975 de 2005, Ley de Justicia y Paz, por la cual se establece la justicia transicional, en el artículo 7 consagra el derecho de la verdad como un derecho inalienable que le asiste a la sociedad y a las víctimas, de conocer la verdad sobre los hechos ocurridos y el paradero de las personas que fueron víctimas de los actos de violencia como la desaparición forzada y los secuestros, ley que entre sus objetivos tiene la reconstrucción de la verdad, que más adelante se complementará con la Ley 1448 de 2011.

Es claro que la Corte Constitucional reconoce el derecho a la verdad como un derecho humano autónomo que al estar enunciado en la Constitución de 1991 $\mathrm{y}$ en los convenios internacionales que están vigentes, se debe entender como un derecho innominado; al hacer parte de los derechos de las víctimas, entendido como un resarcimiento no patrimonial que le asiste a las víctimas por ser Colombia un Estado social de derecho, en donde la reparación y el resarcimiento no sólo debe ser patrimonial sino que también debe estar dentro de la verdad y la justicia. (Corte Suprema de Justicia, Sala Penal, sentencia n. - 26703, 6 de marzo de 2008).

Pero a pesar de que el Estado ha creado mecanismos como la comisión de la verdad y mecanismos para acudir a la justicia, estos tienen falencias porque no cumplen con los requisitos para considerar que se está desempeñando a cabalidad con su obligación, conclusión a la que se llega porque en la actualidad hay muchos actos de violencia que han vulnerado los derechos humanos que están impunes y los familiares aún desconocen el paradero de las víctimas o lo que ocurrió con ellos.

\section{El caso de la Unión Patriótica}

Uno de los casos de violencia más emblemáticos de la historia contemporánea colombiana, es el conocido como el Genocidio Político de la Unión Patriótica, que tiene varias especificidades frente a otros genocidios latinoamericanos. En países como Chile o Argentina fue más que clara la existencia de dictaduras militares, que bajo la consigna de la Seguridad Nacional actuaron de manera brutal durante un tiempo restringido, lo que facilitó de alguna manera la caracterización de los hechos. En Colombia estos hechos podrían constituir genocidios que han sido cometidos bajo la apariencia de un sistema democrático que en el fondo compartía los mismos fines de las dictaduras: "mantener intocables los mecanismos de dominación económica, política y cultural" (Giraldo, 2004).

Bajo este espectro se señala que el Estado colombiano, ha mantenido lineamientos de actuación, durante los últimos cuarenta años, bajo los cuales se ha ido consolidando un marco político, ideológico y cultural desde el que se han fortalecido y legitimado prácticas genocidas (Campos, 2014). Ello significa que, en principio, el sujeto activo del crimen de genocidio en Colombia no sería otro que el Estado.

La identidad negativa. La crisis institucional que se evidencia con la existencia prolongada del conflicto armado en Colombia, deja en el escenario de las posibles motivaciones la cuestión de la persecución política que ha sido una práctica extendida en virtud de la cual es posible señalar, como lo hace Giraldo (2004) que existen políticas asumidas por el Estado desde las cuales se legitiman prácticas como el genocidio. Esto revela tres momentos clave: El primero de ellos, que existe una 
intención clara de exterminar a un grupo específico. El segundo, que dicho exterminio se ejecuta en el marco de la existencia teórica de un Estado democrático. Y tercero, que no se trató de un caso aislado durante un período de gobierno específico, sino que se mantuvo como una política de Estado (Cepeda, 2006, p. 3).

Medina Gallego sostiene que la caída del telón de acero representó también una resignificación de la lucha armada: de la confrontación directa a la confrontación política. Bajo una dinámica de disuasión se inaugura una nueva categoría cuya implicancia es la construcción de una forma diferente de la lucha, ya no insurgente, ya no de carácter político, sino antiterrorista.

El proceso genocida. Las insurgencias habían ido creciendo y fortaleciéndose desde su creación, en concordancia con lo que se ha venido argumentando, existían al menos tres cuestiones estructurales que llevaron justamente a que el conflicto se agudizará: la consolidación territorial de los grupos armados, la conformación de grupos paramilitares y un Estado cada vez más ilegítimo (Centro de Memoria Histórica, 2013). El último aspecto cobra especial relevancia si se ve a la luz de que los acuerdos alcanzados en La Uribe tuvieron más bien poca importancia para las fuerzas militares, las cuales actuaban casi de forma independiente al gobierno (Medina, 2008).

El acuerdo que es objeto del análisis representa el primer acercamiento de un gobierno para zanjar el camino de una democracia efectiva. De acuerdo con las intenciones allí plasmadas los movimientos sociales hasta el momento estigmatizados y perseguidos tendrían derecho a la movilización, de forma tal que las fuerzas armadas, en lugar de perseguirles, los acompañarían y actuarían en favor de garantizar la satisfacción de sus derechos. Pese a las buenas intenciones allí enunciadas, la práctica fue completamente diferente.

De otro lado, las relaciones entre el gobierno y las propias fuerzas militares (quienes representaban en un ancho margen los intereses de unas élites políticas y económicas) estaban tan deterioradas que las prácticas paramilitares no sólo se fortalecían sino que lo hacían a expensas de las mismas Fuerzas Militares, quienes lejos de condenar sus prácticas genocidas las exaltaban (Centro de Memoria Histórica, 2013).

El genocidio a los militantes de la Unión Patriótica, y el asesinato selectivo de militantes de las izquierdas del país (José Antequera -1989-, Diana Cardona -1990-, Jaime Pardo Leal -1987, Bernardo Jaramillo Ossa -1990), fue uno de los golpes más fuertes al esfuerzo democratizador del Estado. El discurso militarista se superpuso al discurso político democrático, legitimando, como se ha mostrado con insistencia, las prácticas genocidas (Cepeda, 2006).

Los resultados de este proceso, al menos en los datos colectados entre los años 85 y 88, dejaron 630 personas asesinadas (Campos, 2014, p. 22). Es así como contra la UP se libra una guerra sucia que va desde los asesinatos, las torturas psicológicas y físicas, el desplazamiento forzado hasta los montajes judiciales (Campos, 2014).

En ese mismo libro, se recogen los testimonios de varios de los sobrevivientes de este proceso, entre ellos el de Imelda Daza, quien señala de manera enfática que no había garantías para ejercer la oposición por la vía legal, de forma que eso llevó a que muchos de los militantes de la Unión Patriótica como el trabajador bancario Ricardo Palmera, decidieran enfilarse en los grupos insurgentes (Campos, 2014).

\section{El encubrimiento}

Como se ha venido mostrando, de acuerdo con lo que señalan autores como Cepeda (2006) y Campos (2014), entre otros; una de las características principales del marco en el cual se desarrolla el proceso genocida en contra de la Unión Patriótica es la existencia, al menos teórica, de una democracia.

A diferencia de lo que habría sucedido Argentina o Chile, Colombia no tenía una 
dictadura y se presentaba ante el mundo como el proceso de consolidación de una democracia del tercer mundo y continuó con esta fachada aun cuando la situación interna del país no distaba mucho de las acciones dictatoriales al interior de los otros países suramericanos, como lo evidencian los casos de desapariciones forzadas, asesinatos selectivos, torturas $\mathrm{y}$ tratos crueles e inhumanos, que eran el pan de cada día en la democracia más estable de América Latina, como lo documentan algunos investigadores.

El Libro Negro de la Represión (1974) dio cuenta de esto de manera contundente en 1978 cuando es finalmente publicado por la Fundación Comité de Solidaridad con los Presos Políticos, allí se afirmaba que la del país no era otra cosa que una "democracia de papel” en la que los medios de comunicación se encargaban de deshumanizar la muerte y ocultar las causas reales por las cuales tantas personas morían o eran desaparecidas diariamente en el país (Políticos, 1974, p. 176).

Esta clase de impunidad busca superarse con la denuncia de los atentados cometidos contra los que formaron parte del movimiento gaitanista y las personas que fueron víctimas del sistema (Pécaut, 2000), es decir, que estuvieron marcados por el asesinato de compañeros de militancia y de familiares integrantes de la Unión Patriótica, pero, en general, se trata de todos aquellos que se atrevieron a dignificar una oposición abierta a los poderes tradicionales. Los medios de comunicación se convirtieron en los dispositivos de encubrimiento, pero también de construcción de representaciones negativas del opositor (Valencia, 2011). Esto es patente en muchos, sino en todos, los testimonios de las víctimas que fueron recogidos por Campos en su libro El Baile Rojo (2014). Según estos, las víctimas no eran mostradas como eran: militantes de un partido legal -como era la UP, sino como guerrilleros cuyo asesinato era representado para el imaginario colectivo como "absolutamente necesario para el bienestar del país". En ese sentido, se considera que el derecho a la verdad debe ser satisfecho tanto a los familiares de quienes fueron víctimas de todas las vejaciones, como a la sociedad colombiana es general.

\section{Genocidio Político - El caso de la UP}

A pesar de que desde 1984 se registran los primeros asesinatos selectivos relacionados con la pertenencia a la nueva fuerza democrática de oposición conocida bajo el nombre de Unión Patriótica (Romero, 2012), y que en el transcurso de sus primeros años fueran asesinadas 630 personas, el primero de los pronunciamientos de la Corte Constitucional en relación con las demandas de la colectividad se hizo hasta 1992 mediante la sentencia T-439 (1992), en la cual la Corte estableció que al ser la finalidad del Estado garantizar la paz entendida como condición de posibilidad para el ejercicio de la democracia y de los derechos fundamentales de los ciudadanos, debería velar por la satisfacción de un mínimo de paz, para aquellos pertenecientes a minorías políticas cuya condición de civil se viere afectado por acciones de carácter militar.

En la demanda presentada por el militante Luis Humberto Rolón Maldonado y expuesta por el magistrado Eduardo Cifuentes Muñoz, la cual se puede leer como el primero de los pronunciamientos legales respecto de la persecución a la que estaba expuesto uno de los integrantes del partido, militante a su vez del Partido Comunista Colombiano (PCC), se afirmó que era tildado de guerrillero y que tuvo que desplazarse forzosamente del país por temor a perder la vida; no obstante, sus familiares siguieron siendo asediados por las fuerzas militares. La Corte estableció que la petición del ciudadano era justa respecto de los fines del Estado social de derecho y adicionalmente hizo un llamado a los jueces de tutela a tener una especial sensibilidad por los derechos fundamentales y su efectiva protección, para lo cual, no basta limitarse a argumentos lógicos o probabilísticos.

En concordancia con lo anterior, la Corte explicita la necesidad que conmina al Estado de investigar y esclarecer debidamente los hechos relacionados con la eliminación sistemática en contra de los militantes de la 
Unión Patriótica y otras minorías políticas bajo las mismas condiciones.

Producto de este requerimiento de la Corte Constitucional el entonces Defensor del Pueblo Jaime Triviño, redacta un informe entregado ante las instancias pertinentes en el cual se determina que existieron, entre los años 1985 y 1992, al menos 717 homicidios contra personas pertenecientes a este tipo de colectividades. Y señala además que de esa cantidad solo un mínimo porcentaje había sido efectivamente investigado y sancionado. Dentro de las recomendaciones que plantea el Defensor está justamente la de presentar ante las instancias internacionales la discusión sobre la existencia del genocidio por razones políticas.

Pese a tales recomendaciones, las cifras ascendentes y el terror derivado de las dinámicas violentas en contra de las colectividades políticas minoritarias, antes que detenerse en nombre de las garantías invocadas, se mantuvo. De acuerdo con las cifras recopiladas por diferentes organizaciones de por lo menos 1598 crímenes a 1997, solo se presentaron 117 sentencias.

Pasaron ocho años hasta que la Corte se volvió a pronunciar y mientras el sistema jurídico y las instancias legales hacían demorar sus declaraciones, las acciones del exterminio seguían su ejecución cabal, a saber, la desaparición de la colectividad política Unión Patriótica por medio del amedrentamiento, los asesinatos selectivos, torturas y/o desapariciones forzosas que se siguieron sumando a la cuenta. Entre 2002 y 2007, el resultado de las indagaciones de la corporación Reiniciar, recogidas por el investigador Yezid Campos en su libro El Baile Rojo (2014), arrojaba 136 homicidios, 38 casos de desaparición forzada y 28 tentativas de homicidio.

\section{La Unión Patriótica en la justicia colombiana}

Dentro del ámbito internacional el Caso de la Unión Patriótica fue recibido por la Corte Interamericana de Derechos
Humanos (CIDH) bajo el rótulo 11.227 el 16 de diciembre de 1993. La alegación colectiva fue presentada por la Corporación Reiniciar y la Comisión Colombiana de Juristas (CCJ), en ella se sostiene precisamente, que el exterminio del Partido legalmente constituido Unión Patriótica es, por la misma forma en la que ha sido ejecutado, un genocidio, cuya particularidad es haber estado motivado por razones políticas.

El proceso alcanzó en 2000 un momento importante, en el cual las partes demandantes y Estado-, bajo la supervisión procesal de la CIDH, llegaron a acuerdos conducentes al esclarecimiento de la verdad en favor de la justicia y la reparación integral, pero tales acuerdos se rompieron en 2006, durante el gobierno de Álvaro Uribe Vélez, porque los demandantes alegaron la inexistente voluntad del Estado en el esclarecimiento de los hechos.

Algunos casos debido a su particular ejecución han sido presentados como causas individuales que también cursan su tránsito en las labores de la CIDH. Casos como el del Senador Iván Cepeda Vargas o el de Álvaro Garcés Parra -asesinado en Sabana de Torres en 1987 (informe no 1/94, 1994)-, suponen avances en materia procesal por cuanto las investigaciones particulares evidencian al Estado colombiano en su inoperancia y negligencia: tanto en las actuaciones que llevan a los hechos en los que resultaron asesinadas las víctimas, como, con posterioridad, en las gestiones en favor del esclarecimiento de la verdad como forma de encontrar un camino hacia la justicia y hacia la reparación integral de las víctimas.

Esto es particularmente claro en la insistencia con la cual la Comisión Interamericana de Derechos Humanos se expresa en sus informes sobre la situación colombiana. La preocupación que les supone el bajo índice de esclarecimiento judicial sobre la mayoría de los hechos denunciados ante esa instancia, algunos de los cuales han corrido trámite a la Corte Interamericana de Derechos Humanos, como consta en el numeral 62 del Informe de la Comisión Interamericana de Derechos Humanos sobre 
el proceso de desmovilización en Colombia publicado el 13 de diciembre de 2004.

\section{CONCLUSIONES}

El delito de genocidio en el ordenamiento jurídico internacional no necesariamente implica impunidad frente a los crímenes cometidos contra los grupos políticos, puesto que la legislación internacional en el Estatuto de Roma lo reconoce y lo sanciona como un delito de lesa humanidad, es decir, como un delito que no solo se comete contra los derechos fundamentales de las víctimas sino contra la humanidad de las mismas.

En Colombia, al igual que el caso armenio, no se ha reconocido por parte del Estado la existencia de genocidio por razones políticas, frente a casos como el de los gaitanistas o la Unión Patriótica, generalmente este tipo de actos atroces se justifican en el hecho de mantener el orden del Estado "en pro del bien común". En otras palabras, se justifica el actuar del Estado como respuesta contra un grupo de oposición.

Frente al caso de la Unión Patriótica que fue el caso más emblemático en relación con este delito, conviene señalar dos aspectos para llegar a la conclusión que se estaba cara al genocidio: el primero de ellos es sobre las avanzadas militares que se hicieron en contra de las personas que representaban la oposición en Colombia y es claro que la oposición no está representada en un grupo poblacional con características raciales, religiosas o nacionales específicas, sino que constituye un espacio diverso de no identificación política con los poderes tradicionales que toman forma con la consolidación de la alianza de la Unión Patriótica (UP).

Es deber de los Estados el velar por el derecho que le asiste a las víctimas en cuanto a la verdad y no solo porque se aplique este derecho, sino hacer la gestión que consiste en investigar los hechos ocurridos, descubrir la identidad de los causantes y que se revelen las circunstancias de modo, tiempo y lugar en que se realizaron los actos de violencia que vulneraron los derechos humanos, que tuvo como resultado la muerte de muchas personas y afectación de otras, en la actualidad hay muchas de ellas que no saben la verdad de lo que sucedió con sus familiares.

El caso de las víctimas de la UP del cual sus derechos a la verdad, justicia y reparación fueron totalmente vulnerados se debe a la ineficacia del Estado por no realizar las investigaciones judiciales, la falta de interés por ser un hecho de hace más de 20 años, las maniobras políticas, entre otras que han hecho que no se aclare lo vivido en esa época en el país, lo que hace sentir por las víctimas de ese suceso que no hubo justicia, verdad, ni reparación.

Una de las preocupaciones que deja esta investigación, es el no reconocimiento por parte de varios Estados acerca de los delitos de genocidio perpetrados hacia los grupos políticos; que para el caso de Colombia a pesar de que la Nación a través de su representante ha pedido perdón a los ciudadanos y víctimas por tan vergonzoso acto contra la humanidad, aún quedan muchos escenarios sin descubrir y muchos capítulos oscuros para las familias de las víctimas, debido a que los casos están inconclusos frente al derecho a la verdad, ya que aún no hay esclarecimiento de los hechos. Las familias perdieron, incluso, el derecho a despedirse de sus seres queridos, lo cual genera impunidad y falta de garantías para ejercer la oposición. 


\section{REFERENCIAS BIBLIOGRÁFICAS}

» Becerra, P., y Pava, E. (2016). Protección del Derecho a la Verdad. Fundamentos jurídicos de la Corte Interamericana de Derechos Humanos. Revista Científica de la universidad autónoma de Manizales, 23 (40) 121- 147. https://bit.ly/2IuA7bn

» Biblioteca Nacional de Colombia. (2020). La violencia. Biblioteca Nacional. https://bit.ly/32v0rcP

» Campos, Y. (2014). El baile Rojo. Norma

» Centro de Memoria Histórica. (2013). ¡BASTA YA! Colombia: memorias de guerra y dignidad. Centro de Memoria Histórica. https://bit.ly/2UdF7UG

» Cepeda, I. (2006). Genocidio político: el caso de la Unión patriótica en Colombia. Revista Cejil, 2, 101 - 112. https://bit.ly/3n8ZMp4

» Comisión Colombiana de Juristas. (2006). Verdad Justicia y Reparación. Algunas preguntas y respuestas. https://bit.ly/36lQcbQ

» Corte Constitucional (1997, 20 de mayo). Sentencia C-239/97 (Carlos Gaviria Díaz, M.P.). https://bit.ly/3n4CHnG

» Corte Constitucional. (1995, 18 de mayo). Sentencia C-225/95. (Alejandro Martínez Caballero, M. P.). https://bit.ly/38x8c5D

» Corte Internacional de Derechos Humanos. (1996). Caso Castillo Páez Vs.Perú. CIDH. https://bit.ly/38uy56l

» Corte Internacional de Derechos Humanos. (1998). Caso Blake VS Guatemala. CIDH. https://bit.ly/35joEEE

$»$ Corte Internacional de Derechos Humanos. (1998). Caso Velásquez Rodríguez Vs. Honduras. CIDH. https://bit.ly/2IrxJ5k

» Dulitzky, A. (2007). 50 años del sistema interamericano de derechos humanos: una propuesta de reflexión sobre cambios estratégicos y necesarios. Instituto Interamericano de Derechos Humanos

» Duran, M. (2015). El genocidio armenio, la pregunta política. Drugstore. https:// bit.ly/3eRIPwO

» Fajardo, A. (2012). Elementos Estructurales del derecho a la Verdad. Civilizar, 12 (22), 15-34. https://bit.ly/3eQGt1e

» Faúndez, H. (2007). El sistema interamericano de protección de los derechos humanos. Aspectos institucionales y procesales. Sistema Interamericano de Derechos Humanos

» Feierstein, D. (2012). Memorias y Representaciones. Sobre la elaboración del genocidio. (1a ed). Fondo de cultura económica de argentina S.A. https://bit. ly/36pADzV

„ Ferraro, D. (2015). Genocidio Armenio. Un siglo de silencio. Noticias Ancap. https://bit.ly/3nfsJ2Y

» Giraldo, J. (2004). La práctica del Genocidio en Colombia. https://bit.ly/2Ii7QFC

» Giraldo, J. (2014). Memory and Reactions of Solidarity to a Horrendous Genocide. Javier Giraldo. https://bit.ly/318IOGW

» González Jáuregui, V. (2008). Impacto del derecho consuetudinario en la conduc- 
ción de hostilidades. CICR

» González, D. (2008). El Derecho a la Verdad en Situaciones de postconflicto Bélico de Carácter no Internacional. Rev. Colomb. Derecho Int, (12) 435 - 468. https:// bit.ly/38vZ01H

» González, F. (2008). La iglesia como actor de la gobernanza en Colombia. IRG. https://bit.ly/38zcTvU

"Granosvky, S. (2014). El Genocidio Silenciado. Holocausto del Pueblo Armenio. Compilación de documentos acerca de la Cuestión Armenia y el Genocidio turco contra el pueblo armenio (1915-1923). Ediciones Continente.

» Guzmán, F. (2012). Derecho a la Verdad y Derecho Internacional. (1a ed). Comisión colombiana de juristas. https://bit.ly/3knEHFP

» Huertas, O. (2006). Aproximaciones al Concepto de Genocidio en Colombia: Un estudio desde el Margen. Revista diálogos saberes, 25, 315 - 334. https://cutt.ly/ zgZRw5l

» Huertas, O., y Cáceres, V. (2015). Genocidio político y derecho penal internacional: análisis desde su exclusión típica. Primici IURIS. https://bit.ly/2Ug710T

» Las 2Orillas. (2014). La Violencia no Empezó con la Muerte de mi Padre. Las 20rillas. https://bit.ly/38wPhbe

» Lemkin, R. (2008). El Dominio del Eje sobre la Europa Ocupada. Prometeo libros.

» Medina, C.,y Nash, C. (2007). Sistema Interamericano de Derechos Humanos: introducción a sus mecanismos de protección. Universidad de Chile

» Morgenthau, H. (1975). Testimonio Sobre el Genocidio cometido por los Turcos Contra el Pueblo Armenio. Comisión Pro Causa Armenia de la América Latina.

» Nuñez, S. (2011). Interpretación y aplicación del Derecho Internacional Humanitario en el sistema interamericano de Derechos Humanos. CIDH. https://bit. ly/2IhZfmk

» Oquist, P. (1978). Violencia, conflicto y política en Colombia. Instituto de Estudios Colombianos, Banco Popular.

» Organización de Naciones Unidas. (1998). Estatuto de Roma de la Corte Penal Internacional. Un. https://bit.ly/3eGg6dY

» Organización de Naciones Unidas. (2018). La convención para la prevención y sanción del delito de genocidio, 1948-2018. Un. https://bit.ly/32qQfSA

» Papa Francisco I. (2016). Papa condena genocidio armenio causado por el Imperio Otomano. Tele Sur Tv. https://bit.ly/3llqw5t

» Paredes, R. (2006). Exclusión de los Grupos Políticos en la Tipificación Internacional del Genocidio. Rigoberto Paredes y Asociados.

» Pécaut, D. (2003). "Memoria imposible, historia imposible, olvido imposible". Violencia y política en Colombia. Elementos de reflexión, Medellín, Hombre nuevo, Univalle, 113-133.

» Pérez, T. (2013). La justicia transicional y el caso colombiano: El derecho a la verdad como pilar fundamental para lograr la justicia y la reparación. Suma de Negocios, 4 (1), 9- 20. https://bit.ly/2JYilyd

» Rincón, T. (2010). Verdad, Justicia y reparación. La Justicia Transicional. [Tesis, 
Universidad del Rosario]. Repository Rosario. https://bit.ly/36sc05K

» Romero, R. (2012). Unión Patriótica expedientes contra el Olvido. Periodicas S.A.S.

» Rousseau, J. (2000). Emilio, o de la educación. (Trad. Ricardo Viñas). El aleph. https://bit.ly/36g4Q4t

» Ruiz, R. (2014). Castigar el negacionismo. El país. https://bit.ly/2IgGrnt

» Salmón, E. (2004). Introducción al Derecho. Internacional Humanitario. CHDH. https://bit.ly/2GOVeVs

» Uribe, M. (2004). Antropología de la Inhumanidad. Norma.

» Valencia, M. (2011). El Genocidio al Movimiento Gaitanista. El Espectador. https://bit.ly/2Irlfen

»Vallejo, V. (2016). En Colombia hay un historicidio sistemático: Gloria Gaitán. Radio Nacional. https://bit.ly/32ASUt0 